\title{
Erratum to: Assessment of the novel tubulin-binding agent EHT 6706 in combination with ionizing radiation or chemotherapy
}

Céline Clémenson • Cyrus Chargari • Laurent Désiré • Anne-Sophie Casagrande • Jean Bourhis • Eric Deutsch

Published online: 6 March 2012

(C) Springer Science+Business Media, LLC 2012

Erratum to: Invest New Drugs

DOI 10.1007/s10637-011-9785-3

In the original version of this article, Figure 6 is not correct and shows two identical graphs for MiaPaca2 cell line. Here is included the proper graphs depicting all tested schedules in clonogenic assay for this cell line.

The online version of the original article can be found at http://dx.doi. org/10.1007/s10637-011-9785-3.

C. Clémenson • C. Chargari · J. Bourhis · E. Deutsch INSERM U1030, Radiothérapie Moléculaire, Institut Gustave Roussy, Université Paris XI,

Villejuif, France

C. Chargari

Service d'Oncologie Radiothérapie,

Hôpital d'Instruction des Armées du Val-de-Grâce,

Paris, France

L. Désiré · A.-S. Casagrande

Exonhit SA,

Paris, France

J. Bourhis $\cdot$ E. Deutsch

Département de Radiothérapie, Institut Gustave Roussy,

Villejuif, France

E. Deutsch $(\bowtie)$

INSERM U1030, Institut Gustave Roussy,

114, rue Edouard Vaillant,

94805 Villejuif Cedex, France

e-mail: eric.deutsch@igr.fr 
Fig. 6 Schedule dependence of the EHT 6706 radiosensitizing effect in H460 and MiaPaca2 cells. Cells were treated with different schedules. Cellular colonies were colored and counted after 10 days of incubation. SFs were normalized to the SF of the corresponding non-treated nonirradiated cells. a schematic representation of the different treatment schedules; b clonogenic survival curves of normalized SFs; c Sensitivity Enhancement Ratios (SERs) of the different treatments



b
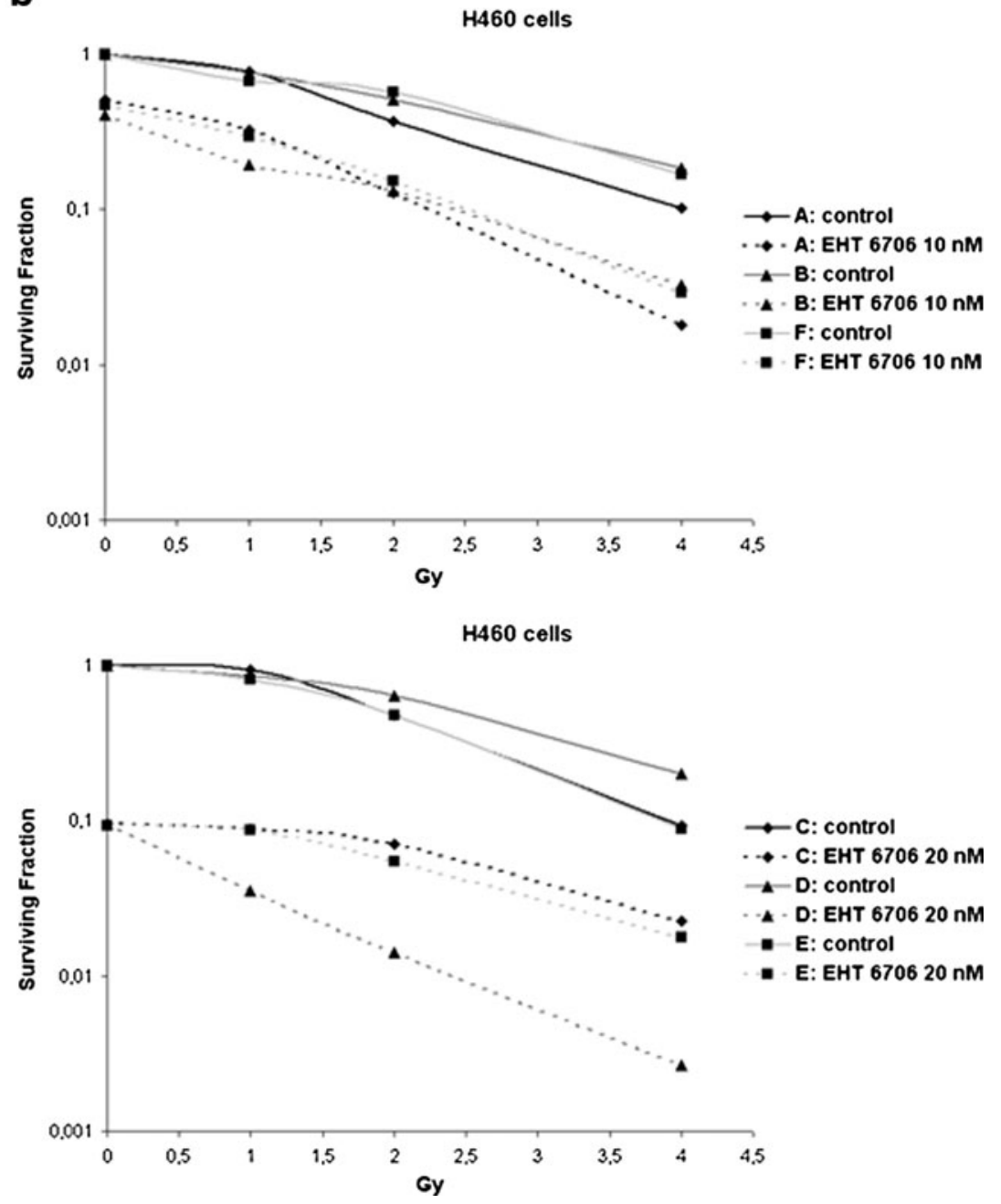
Fig. 6 (continued)
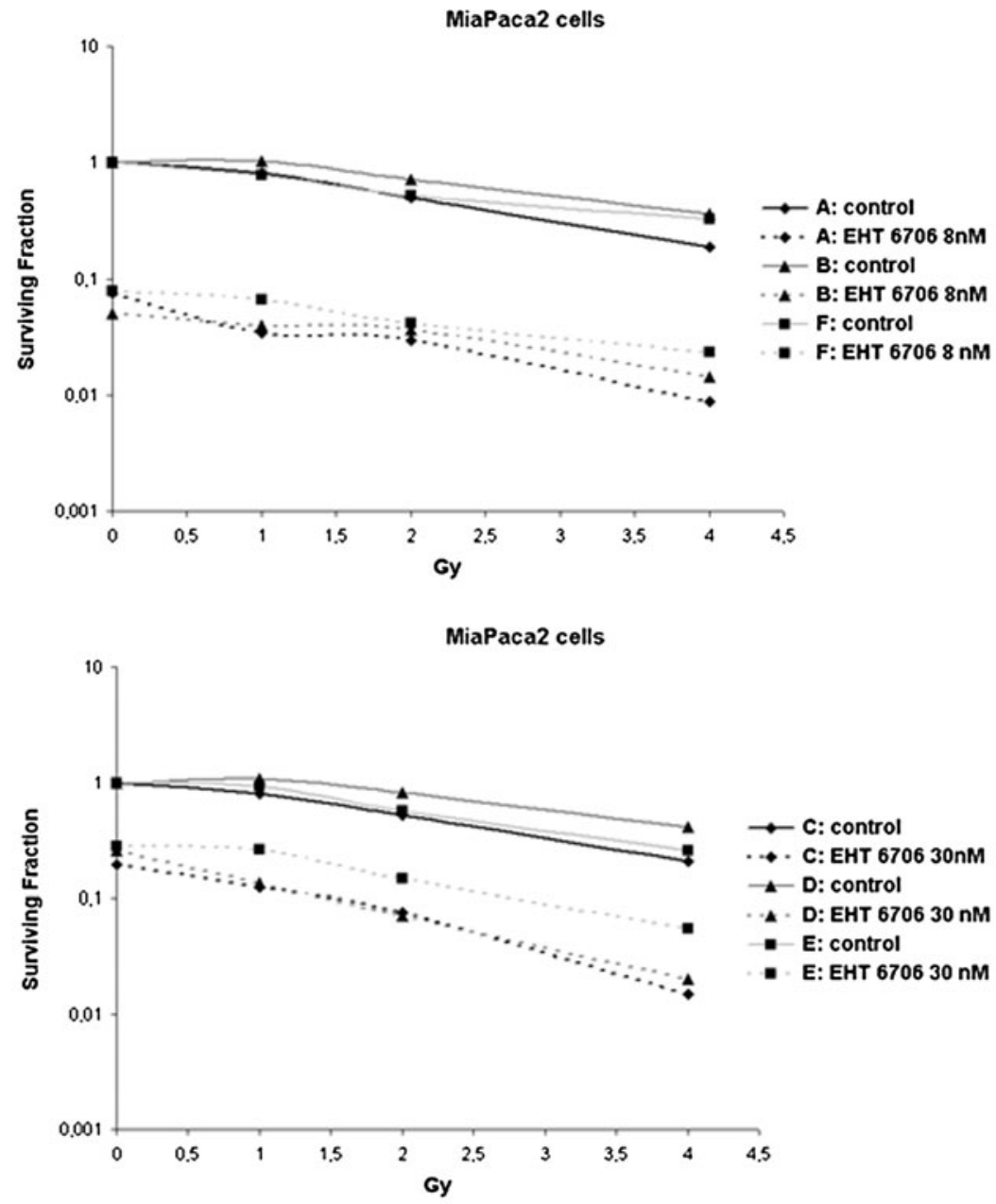

C

\begin{tabular}{lll}
\hline Sequences & $\begin{array}{l}\text { SER (1 Gy) in } \\
\text { H460 cells }\end{array}$ & $\begin{array}{l}\text { SER (1 Gy) in } \\
\text { MiaPaca2 cells }\end{array}$ \\
\hline A: irradiation then treatment with EHT 6706 & 1.23 & 1.79 \\
20h later & & 1.29 \\
B: treatment with EHT 6706 then irradiation & 1.60 & 1.25 \\
$\quad$ 20h later & 1.02 & 2.03 \\
$\begin{array}{l}\text { C: irradiation then 20h later treatment with } \\
\text { EHT } 6706 \text { for 20h, then drug removed }\end{array}$ & 2.28 & 1.00 \\
$\begin{array}{l}\text { D: treatment with EHT } 6706 \text { for 20h, then dng } \\
\text { removed and irradiation }\end{array}$ & 0.28 \\
$\begin{array}{l}\text { E: irradiation and immediate treatment with } \\
\text { EHT } 6706 \text { for 20h, then drug removed }\end{array}$ & 0.86 & 1.07 \\
$\begin{array}{l}\text { F: irradiation and immediate treatment with } \\
\text { EHT } 6706\end{array}$ & 1.07 & 0.92 \\
\hline
\end{tabular}

